\title{
Do repeated adenoidctomy challenging the post adenoidectomy bleeding control
}

\begin{abstract}
Objective: The aim of this study was to analyse the data of patients underwent adenoidectomy in Otorhinolaryngological practice, and determine the incidence of adenoid regrowth after adenoidectomy evaluate complications of surgery\& challenging in management of these complications.

Setting: Tertiary referral centre.

Methods: Retrospective study over 5 years of all adenoidectomy cases at Aseer central hospital during the period from January 2013 to January 2017. Patient's demographic data, recurrent cases and post op complications were analysed.

Results: A total 201 cases underwent adenoidectomy 117 (58.2\%) Male and 84(41.8\%) were female. The age range was from 1 year to 9year; . shows that $98.0 \%$ of the sample have (No Recurrence), 2.0\% ( 4 cases ) have (Recurrence Underwent 2ND Adenoidctomy.95.5\% of the sample don't have complications, $4.5 \%$ ( 9 cases ) have (complications)which is bleeding per mouth , 7 cases managed surgically and 2 cases managed conservative.
\end{abstract}

Conclusion: Adenoid regrowth after adenoidectomy is rare about $2 \% \&$ most common complications noticed is bleeding per mouth.

Keywords: adenoid regrowth, post op bleeding, surgical management
Volume I2 Issue 2 - 2020

\author{
Abdelaziz Qobty, 'Ali S Al-Qahtani, ${ }^{2}$ Ali \\ Almothahbi, ${ }^{3}$ Nadiah Al Hariri ${ }^{4}$ \\ 'ENT Surgeon Kku, Kingdom of Saudi Arabia \\ ${ }^{2}$ Associate Professor of ORL-HNS at Aseer Central hospital, \\ Kingdom of Saudi Arabia \\ ${ }^{3}$ ENT Surgeon at Aseer Central Hospital Abha, Kingdom of \\ Saudi Arabia \\ ${ }^{4}$ Medical Student College of Medicine, King Khalid University \\ Abha, Kingdom of Saudi Arabia
}

Correspondence: Abdelaziz Qobty, King Khalid University, Abha City, Kingdom of Saudi Arabia, Tel +96650 I 5 I09II, Email abd.qobt@gmail.com

Received: March 24, 2020| Published: April 15, 2020

\section{Introduction}

Adenoid regrowth after adenoidectomy is rare the aim of this study was to analyse the data of patients underwent adenoidectomy in Otorhinolaryngological practice, and determine the incidence of adenoid regrowth after adenoidectomy evaluate complications of surgery.

\section{Methods}

Research approved by Ethics \& research Committee of Aseer tertiary Hospital, Abha, city in Saudi Arabia, we reviewed the files of all patients who underwent adenoidectomy between 2013 -2017 were analysed.

\section{Results}

A total 201 cases underwent adenoidectomy 117(58.2\%) Male and $84(41.8 \%)$ were female. The age range was from 1 year to 9 year. shows that $98.0 \%$ of the sample have (No Recurrence), $2.0 \%$ (4 cases) have (Recurrence Underwent 2ND Adenoidctomy. 95.5\% of the sample don't have complications, $4.5 \%$ (9 cases) have (complications) which is bleeding per mouth, 7 cases managed surgically and 2 cases managed conservative (Tables 1-6). In recurrent cases surgeon faced no difficulty in controlling the bleeding (Figures 1-6). ${ }^{1-10}$

\section{Discussion}

The adenoid, It is a soft tissue swelling located in the nasopharynx. Excsion of the adenoid is a operation known adenoidectomy. Adenoiditis may cause symptoms like purulent rhino rhea .Adenoidectomy is the surgical excision of the adenoid for alot of causes include nasal obstruction with mouth breathing, recurrent infections, or persistant otitis media with effusion. The adenoid is much less in adult which regress in this age group or absent and more common in children which consider one of the most paediatric elective surgeries.

Table I Shows that $41.7 \%$ of the sample are (3-6 years), 34.3\% (>6years) and $22.5 \%$ (<3years) as shown as in Figure I

\begin{tabular}{lll}
\hline \multicolumn{2}{l}{ Distribution of the sample by age } \\
\hline Age & Frequency & Percent \\
\hline$<3$ years & 46 & 22.5 \\
3-6 years & 85 & 41.7 \\
$>6$ years & 70 & 34.3 \\
Total & 201 & 98.5 \\
\hline
\end{tabular}

Table 2 Shows that $58.2 \%$ of the sample are (Male), $41.8 \%$ Female) as shown as in Figure 2

\begin{tabular}{lll}
\hline \multicolumn{2}{l}{ Distribution of the sample by Gender } \\
\hline Gender & Frequency & Percent \\
\hline Male & 117 & 58.2 \\
Female & 84 & 41.8 \\
Total & 201 & 98.5 \\
\hline
\end{tabular}


Table 3 shows that $98.0 \%$ of the sample have (No Recurrence), $2.0 \%$ have

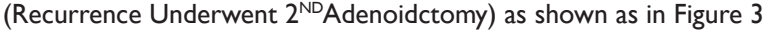

\section{Distribution of the sample by Recurrence}

\begin{tabular}{lll}
\hline Recurrence & Frequency & Percent \\
\hline No recurrence & 197 & 98.0 \\
Recurrence underwent 2NDadenoidectomy & 4 & 2.0 \\
Total & 201 & 100.0 \\
\hline
\end{tabular}

Table 4 Shows that $95.5 \%$ of the sample don't have complications, $4.5 \%$ have (complications) as shown as in Figure 4

\section{Distribution of the sample by complications}

\begin{tabular}{lll}
\hline Complications & Frequency & Percent \\
\hline No & 192 & 95.5 \\
Yes & 9 & 4.5 \\
Total & 201 & 100.0 \\
\hline
\end{tabular}

Table 5 Shows that 66.67 of the complications are (Primary Hemorrage), 33.33 of the complications are (Secondary Hemorrage) as shown as in Figure 5

\begin{tabular}{lll}
\hline Distribution of the sample by Hemorrage & \\
\hline Hemorrage & Frequency & Percent \\
\hline Primary hemorrage & 6 & 66.67 \\
Secondary hemorrage & 3 & 33.33 \\
Total & 9 & 100.0 \\
\hline
\end{tabular}

Table 6 Shows that $96.02 \%$ of the sample are (No Hemorrage), I\% of cases managed conservarive, 3.5 of cases managed in OR as shown as in Figure 6

\begin{tabular}{lcl}
\hline \multicolumn{2}{l}{ Distribution of the sample by complications } & \\
\hline Post op hemorrage management & Frequency & Percent \\
\hline No hemorrage & 192 & 96.02 \\
Conservative managment & 2 & 1.00 \\
Surgical managment & 7 & 3.5 \\
Total & 201 & 100.0 \\
\hline
\end{tabular}

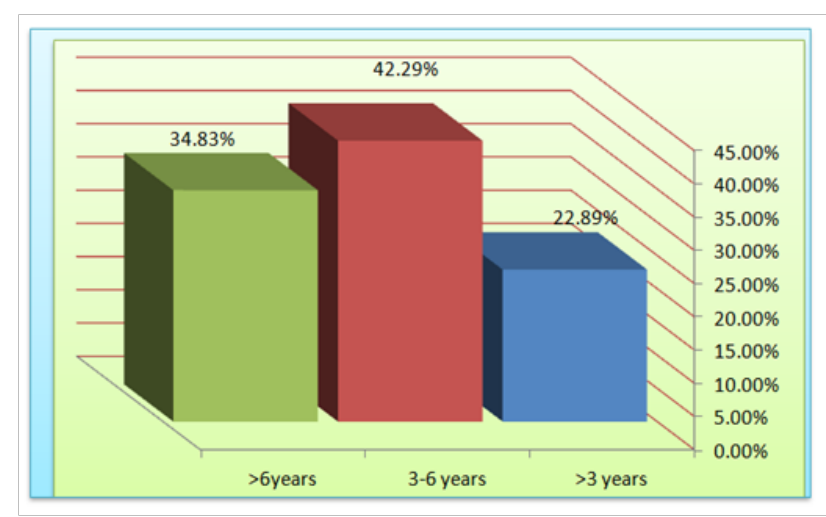

Figure I Distribution of the sample by age.

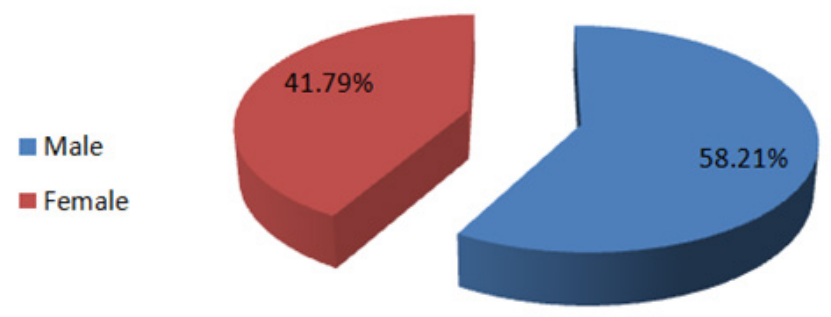

Figure 2 Distribution of the sample by Gender.

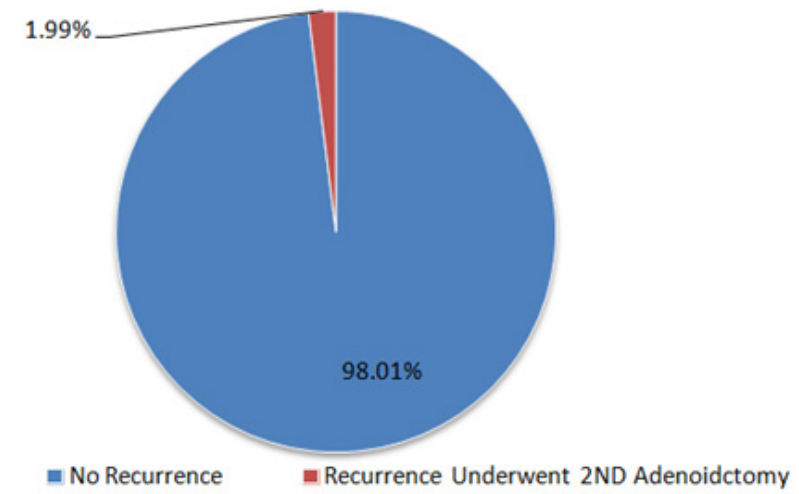

Figure 3 Distribution of the sample by Recurrence.

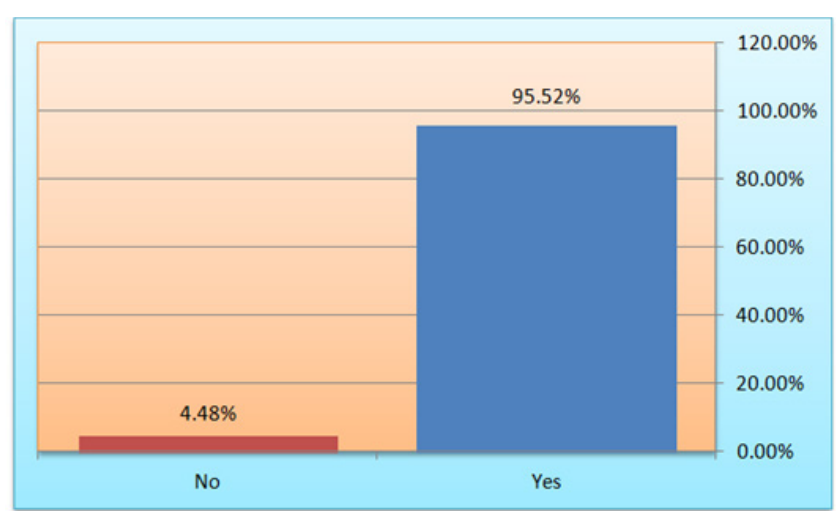

Figure 4 Distribution of the sample by Complications.

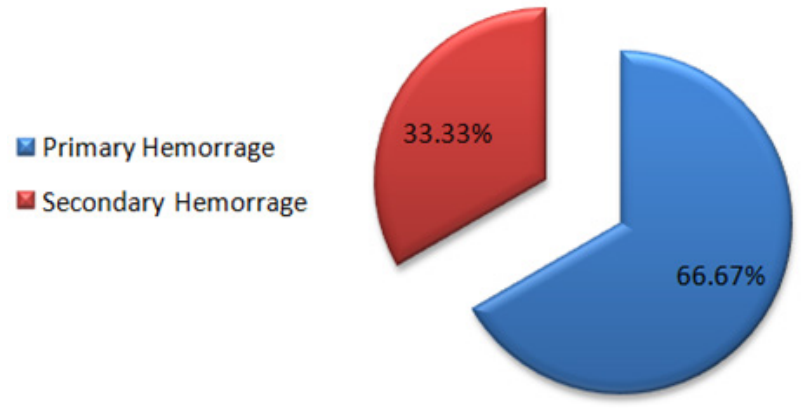

Figure 5 Distribution of the sample by Hemorrage. 


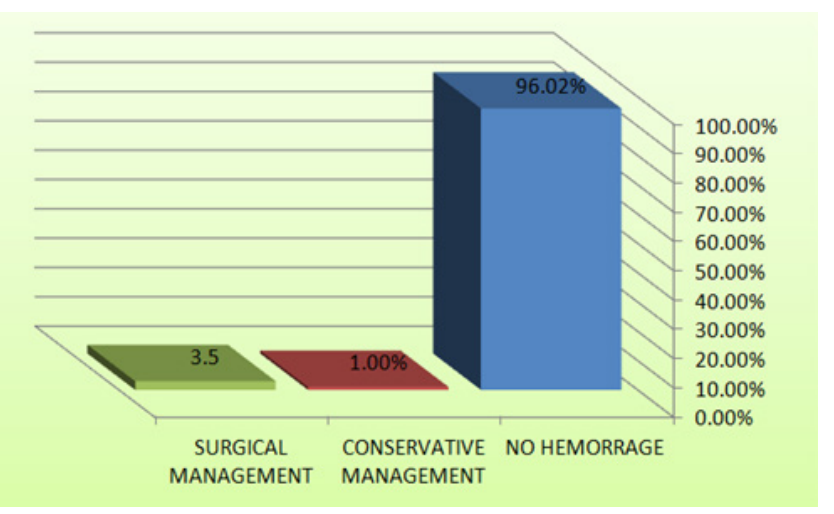

Figure 6 Distribution of the sample by (Post op Hemorrage Management).

\section{Conclusion}

Adenoid regrowth after adenoidectomy is rare about $2 \%$ \& Most common complications noticed is bleeding per mouth which is life threating condition need urgent treatment other conservative or surgically control in OR, study shows no significant difficulty in management between post adenoidectomy bleeding as first time or recurrence cases, recurrent cases seem not challenging the surgeon to manage the complications.

\section{Acknowledgments}

The author has no acknowledgments.

\section{Conflict of interest}

The author declares that there is no conflict of interest to disclose.

\section{Funding}

None.

\section{References}

1. Tuner K, Nord CE. Emergence of beta-lactamase producing anaerobic bacteria in the tonsils during penicillin treatment. Eur J Clin Microbiol. 1986;5(4):399-404.

2. Brook I, Yocum P. Comparison of the microbiology of group A and non-group A streptococcal tonsillitis. Ann Otol Rhinol Laryngol. 1988;97(3):243-246.

3. Tuner K, Nord CE. Betalactamase-producing microorganisms in recurrent tonsillitis. Scand J Infect Dis Suppl. 1983;(suppl 39): 83-85.

4. Kielmovitch IH, Keleti G, Bluestone CD, et al. Microbiology of obstructive tonsillar hypertrophy and recurrent tonsillitis. Arch Otolaryngol Head Neck Surg. 1989;115(6):721-724.

5. Brook I. Aerobic and anaerobic bacteriology of adenoids in children: A comparison between patients with chronic adenotonsillitis and adenoid hypertrophy. Laryngoscope. 1981;91(3):377-382.

6. Kaplan EL, Johnson DR. Eradication of group A streptococci from the upper respiratory tract by amoxicillin with clavulanate after oral penicillin V treatment failure. J Pediatr. 1988;113(2):400-403.

7. Brook I. Treatment of patients with acute recurrent tonsillitis due to group A beta-haemolytic streptococci: A prospective randomized study comparing penicillin and amoxycillin/clavulanate potassium. $J$ AntimicrobChemother. 1989;24(2):227-233.

8. Kornblut AD. A traditional approach to surgery of the tonsils and adenoids. OtolaryngolClin North Am. 1987;20(2):349-363.

9. Brook I. The role of beta-lactamase-producing bacteria in the persistence of streptococcal tonsillar infection. Rev Infect Dis. 1984;6(5):601-607.

10. Brook I, Gober AE. Emergence of beta-lactamase-producing aerobic and anaerobic bacteria in the oropharynx of children following penicillin chemotherapy. ClinPediatr (Phila). 1984;23:338-341. 